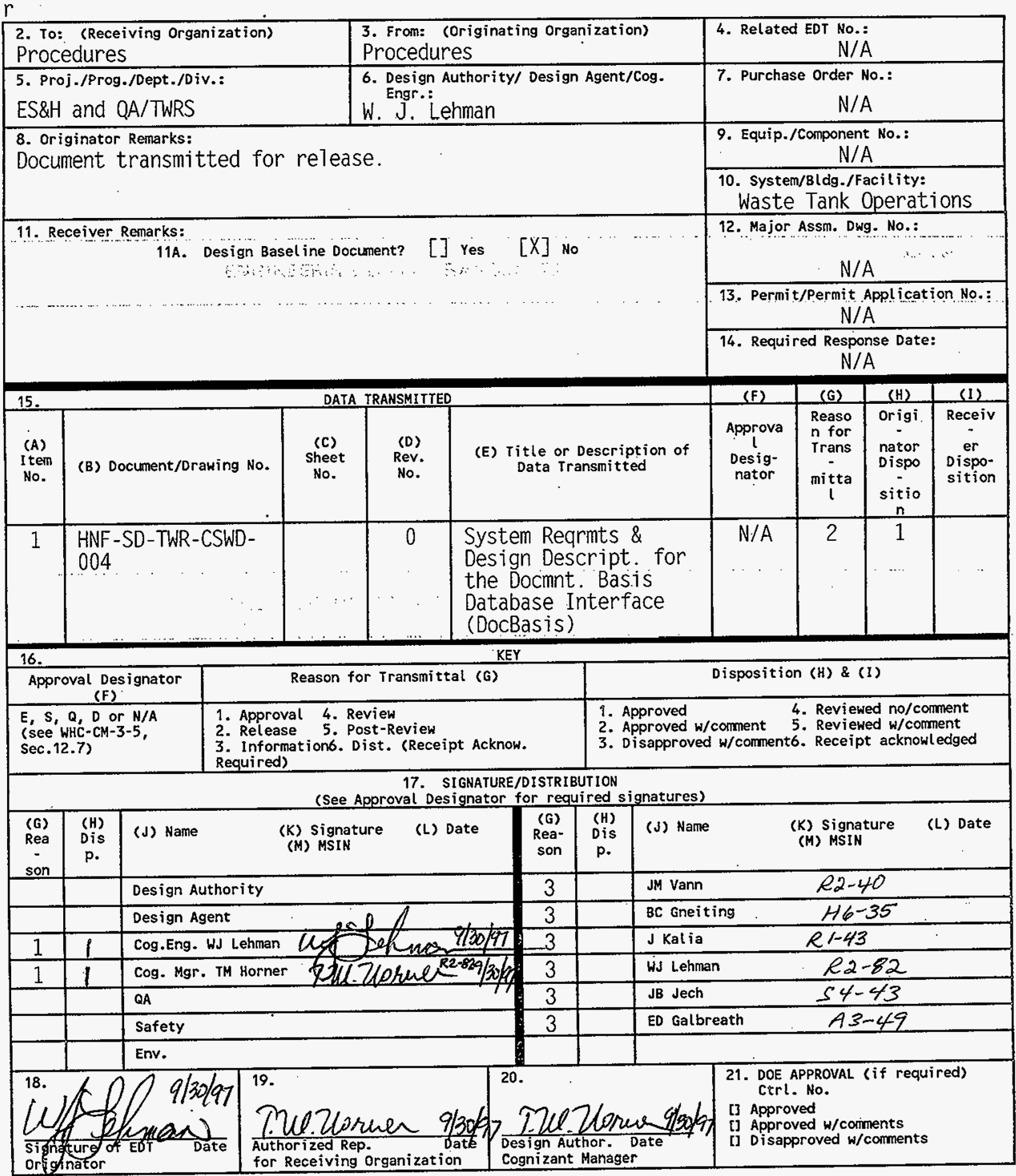




\title{
System Requirements and Design Description for the Document Basis Database Interface (DOCBASIS)
}

\author{
W. J. Lehman \\ Lockheed Martin Hanford Corporation, Richland, WA 99352 \\ U.S. Department of Energy Contract DE-AC06-96RL13200
EDT/ECN: $617398 \quad$ UC: 905
Org Code: $70340 \quad$ Charge Code: DIN85
B\&R Code: EW3120075 Total Pages: 14

Key Words: DOCBASIS, Procedures, Document Basis

Abstract: This document describes system requirements and the design description for the Document Basis Database Interface (DocBasis). The DocBasis application is used to manage procedures used within the tank farms. The application maintains information in a small database to track the document basis for a procedure, as well as the current version/modification level and the basis for the procedure. The basis for each procedure is substantiated by Administrative, Technical, Procedura1, and Regulatory requirements. The DocBasis user interface was developed by Science Applications International Corporation (SAIC).

TRADEMARK DISCLAIMER. Reference herein to any specific commercial product, process, or service by trade name, trademark, manufacturer, or otherwise, does not necessarily constitute or imply its endorsement, recomendation, or favoring by the United States Governinent or any agency thereof or its contractors or subcontractors.

Printed in the United States of America. To obtain copies of this document, contact: Document Control Services, P.0. Box 950, Mailstop H6-08, Richland WA 99352, Phone (509) 372-2420; Fax (509) 376-4989.
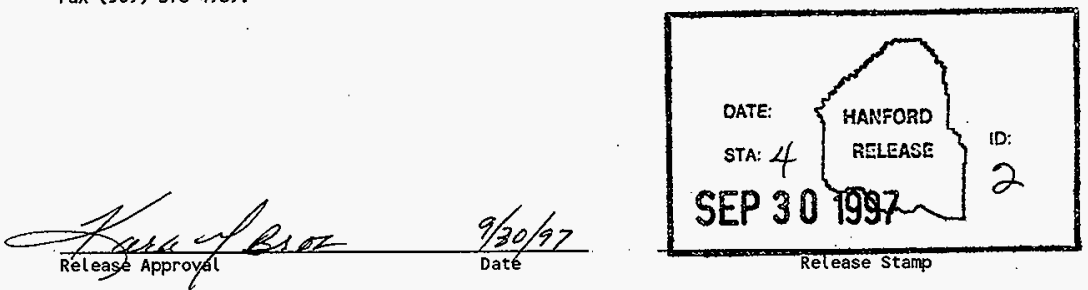

\section{Approved for Public Release}


HNF-SD-TWR-CSWD-004, Rev. 0

\title{
SYSTEM REQUIREMENTS AND DESIGN DESCRIPTION FOR THE DOCUMENT BASIS DATABASE (DocBasis)
}

\author{
Prepared by \\ Science Applications International Corporation \\ Richland, Washington 99352 \\ Prepared for \\ Procedures Group \\ Tank Waste Remediation System \\ Hanford Site, Richland, Washington 99352
}


Table of Contents

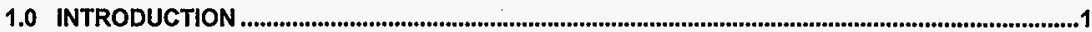

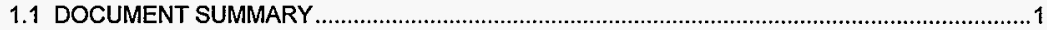

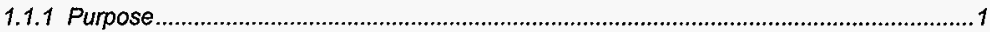

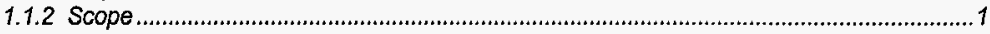

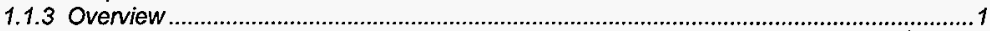

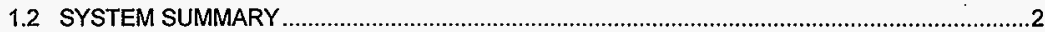

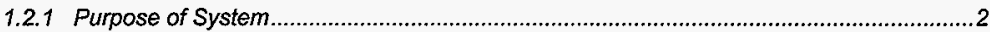

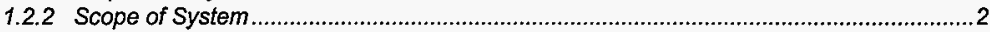

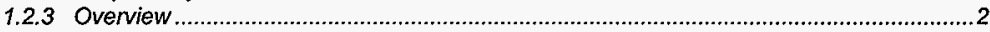

1.3 DEFINITIONS

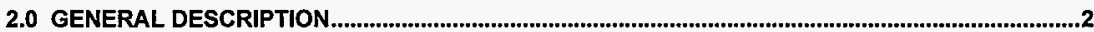

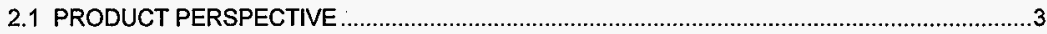

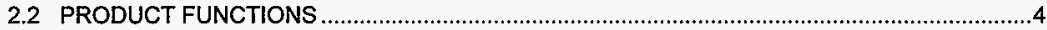

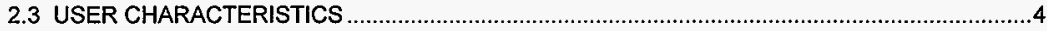

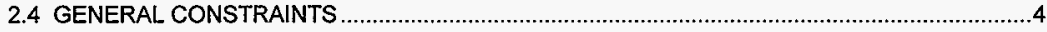

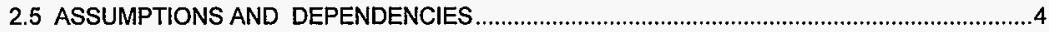

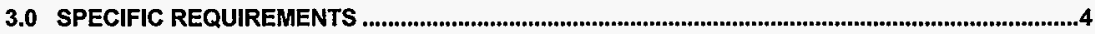

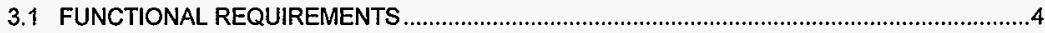

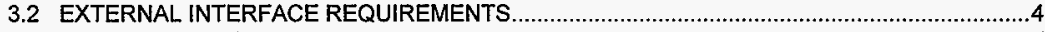

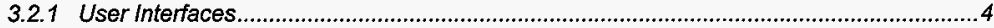

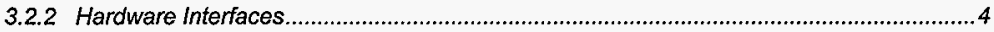

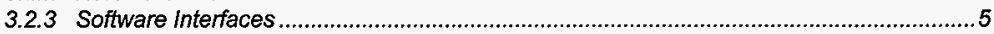

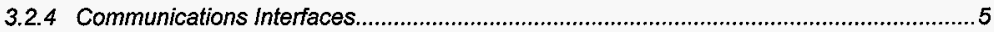

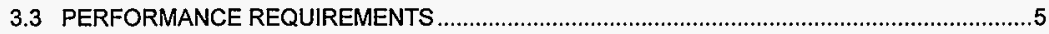

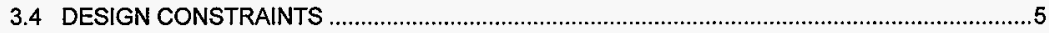

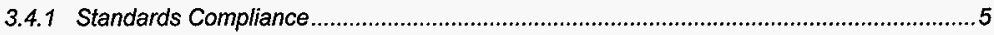

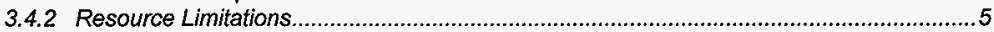

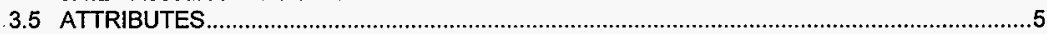

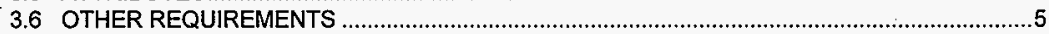

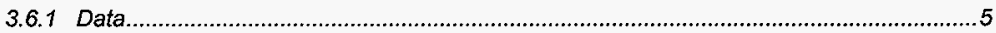

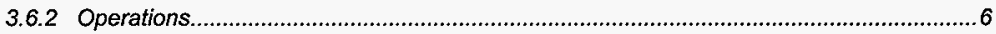

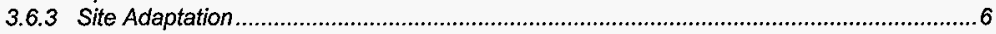

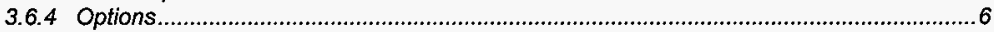

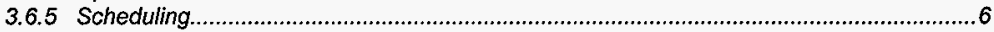

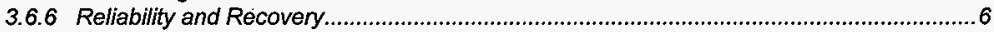

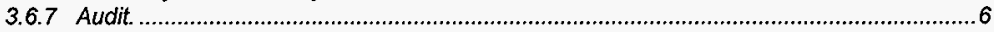

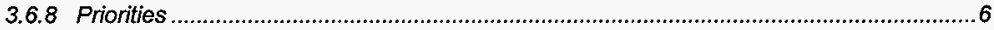

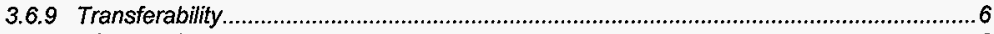

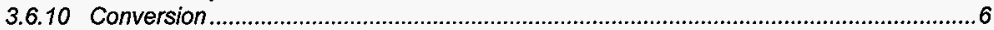

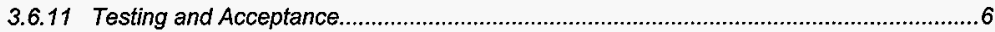

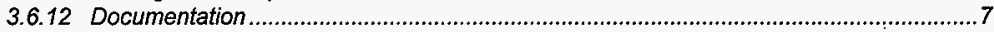

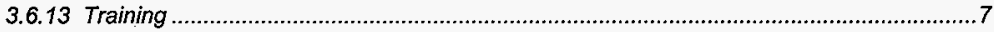

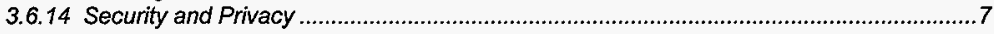

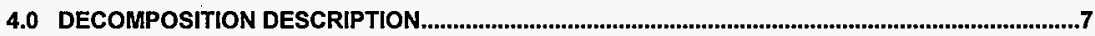

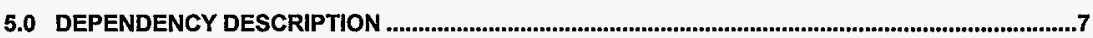

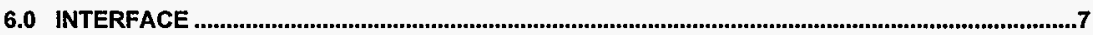

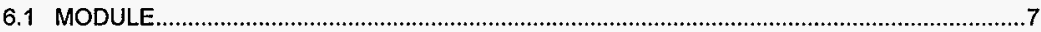

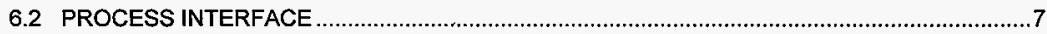




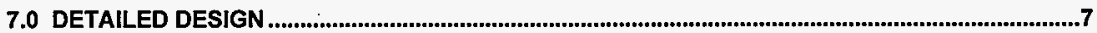

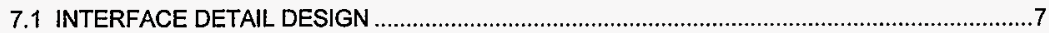

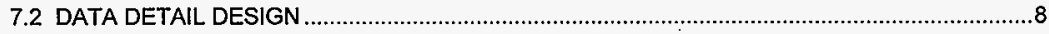

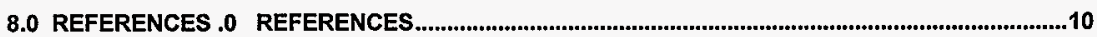

Tables

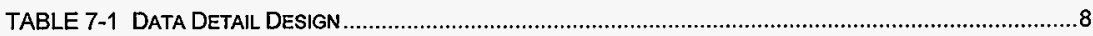

Figures

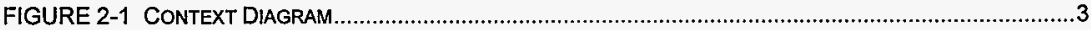

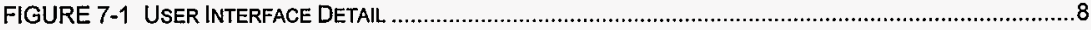




\subsection{INTRODUCTION}

The Tank Farm Procedures implement requirements that are necessary to ensure that waste tank operations are conducted within a safe operating envelope protecting the worker, the public, and the environment. In order to maintain the Tank Farms Procedures and ensure operations are being conducted in accordance with up-to-date- procedures, Tank Farms needs an easy to use, automated tool that would provide management and cognizant engineers, and safety and licensing personnel easy access to procedure information.

\subsection{DOCUMENT SUMMARY}

\subsubsection{Purpose}

The objective of the Software Requirements and Design Description (SRDD) document is to describe the functional and performance requirements for DocBasis and to document the design features in such a manner so as to support future maintenance activities. The document includes a detailed description of features designed to assist Tank Farm procedures personnel. The design portion of this document includes a detailed description of the control flow, data flow, control logic, and data structures used to program the software.

This document is intended to define the system features included in the DocBasis database as well as to provide information necessary to modify the design and perform upgrades. This document is intended for use by Tank Farm management and database administration personnel in accessing site and facility information and coordinating the integration of Tank Farm regulatory analysis and assessment databases. This document has been produced in compliance with WHC-CM-3-10 Software Practices SP3.1 (HNF-PRO-429) following the outline provided in the Statement of Work dated May 1, 1997.

This document describes how DocBasis provides an automated tool for the Tank Farm Waste Remediation System (TWRS) Procedures Group to track and document procedure revisions and bases and perform other procedure maintenance activities. Design description specifications are outlined in the following document sections.

\subsubsection{Scope}

The scope of the SRDD is to describe performance requirements and design features in such a manner as to allow a database administrator to understand how to access information contained in DocBasis and integrate that information into other site or facility databases. The document will describe the requirements which formed the basis for the development of the software and special design methods used to protect data integrity and support data validation. Detailed users instructions or programming manual information are out of scope and not included in this document

\subsubsection{Overview}

The SRDD is organized into seven basic sections. The first two sections provide a general description of DocBasis and the factors that lead its development. The third section provides a detailed description of the functional and performance requirements that lead to the design of the database. Sections 4 through 6 provide a description of software decomposition, dependency and interfaces. And Section 7.0 provides a description of the detailed design for DocBasis.

Section 1.0 and 2.0 will be most useful to Tank Farm Management personnel in order to understand the program requirements that drive the cievelopment of the software. Understanding the program "drivers" is essential in developing facility-wide or site-wide plans for integrating regulatory requirement databases. Sections $4.0,5.0$ and 6.0 describe software decomposition, dependency and interfaces that are important to understanding how information is accessed and stored in the database. 
These sections will be most useful to the database administrator tasked with coordinating the integration of Tank Farm regulatory requirement databases. Section 7.0 provides detailed design information which programming personnel will need to further upgrade or maintain the database.

\subsection{SYSTEM SUMMARY}

This section will describe the purpose of DocBasis, the scope of system products and the business processes directly supported by the system. The section will outline the computer hardware and software requirements for DocBasis and summarize customer needs that were the basis for software production.

\subsubsection{Purpose of System}

The DocBasis database is used to support the Proclnfo and ARMI applications to support the authorization basis and the document basis requirements established in WHC-CM-3-5, Section 12.5, Document Control.

\subsubsection{Scope of System}

DocBasis was developed by the Procedures group of the Tank Waste Remediation System (TWRS) Program. The DocBasis application is used to manage procedures used within the tank farms. The application maintains the document basis for the procedure as well as the current version/modification level and the basis for the procedure. The basis for each procedure is substantiated by Administrative, Technical, Procedural, and Regulatory requirements.

\subsubsection{Overview}

As indicated in section 1.1, the Tank Farms Authorization Basis identifies the applicable safety requirements for Tank Farms. However, simply identifying the requirements will not assure that facility operations adhere to the requirements. Once the requirements are identified, the next important activity is to determine if sufficient procedures exist to implement the requirement. By providing a method for documenting the results of the procedure compliance assessment, management will be able to clearly identify areas where inadequate or incomplete procedures exist. This effort will also identify redundant or out-dated procedures and/or manuals that are no longer required to meet facility objectives

Once a complete set of procedures is identified as sufficient to implement the Authorization Basis requirements, then on-going verification is needed to ensure that procedure revisions do not reduce the level of safeguards intended by the requirements. By tracking the specific sections of an implementing procedure against the Authorization Basis requirement they support, the effects of a procedure change can be quickly evaluated.

Providing an automated template to guide data entry reduces data entry errors and improves assessment evidence rigor. Providing electronic storage and access to assessment data reduces data entry requirements as common data may be electronically "linked" and incorporated quickly and efficiently.

\subsection{DEFINITIONS}

User/System Administrator: One who maintains data quality provides system oversight and maintenance.

\subsection{GENERAL DESCRIPTION}

The DocBasis database is used to support the Proclnfo and ARMI applications in support the authorization basis and the document basis requirements established in WHC-CM-3-5, Section 12.5 , Document Control. The DocBasis application is used to manage procedures used within the tank farms. 
The application maintains the document basis for the procedure as well as the current version/modification level and the basis for the procedure. The basis for each procedure is substantiated by Administrative, Technical, Procedural, and Regulatory requirements.

\subsection{PRODUCT PERSPECTIVE}

As TWRS attempts to achieve an integrated safety management system, a basic tenant is that facility workers have the ability to trace work practices back to requirement drivers. This necessitates that requirement management databases be linked to other databases that assist conduct of work and documentation tools used by facility personnel. Examples of these tools include: the master equipment list (MEL), the Environmental Requirements Management Interface (ERMI), Procedure Information, Engineering Release System Data Base or Hanford Document Control System, and Requirements Management and Assured Compliance System (RDD100).

DocBasis addresses the following needs that were identified by TWRS:

- Electronic data storage,

- Efficient access to procedure status related to Authorization Basis compliance, and

- Reduced data entry through relational links, document loading functions, pick lists and other data controls.

FIGURE 2-1 Context Diagram

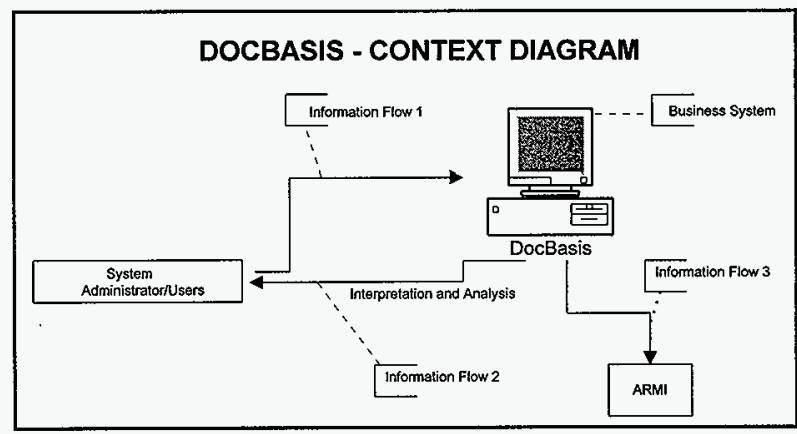

\section{Business System}

The ARMI sofware facilitates requirement maintenance, classification to tank structures and systems element, and procedure compliance. The following external interfaces and information flows describe how these functions are accomplished.

\section{External Entities}

System Administrator/ User

Maintain data quality

ARMI System Administrator

Read data and report any data discrepancies. 
Information Flows

Information Flow 1

Users are responsible for data quality and accuracy with respect to data input.

Information Flow 2 Information to user groups for procedure tracking and accuracy verification.

Information Flow $3 \quad$ Procedure information output to external databases.

\subsection{PRODUCT FUNCTIONS}

DocBasis functions are the information flow as described in Section 2.1.

\subsection{USER CHARACTERISTICS}

Users of DocBasis include procedure organization personnel and external users that wish to access information contained within the database.

\subsection{GENERAL CONSTRAINTS}

No limitations are imposed by other business functions or contractual obligations. Because the ARMI software does not meet the definition of quality-affecting software according to Project Hanford Management Contract (PHMC) procedures, and because the software development costs are under $\$ 40,000$, formal verification and validation documents are not required. Informal verification and validation documents are maintained by developers and can be provided upon request.

\subsection{ASSUMPTIONS AND DEPENDENCIES}

Since DocBasis is an Access 2.0 databases, an OS/2 server should not be used. Developers have detected record locking problems with this configuration. Therefore, it is recommended that the database reside on a Windows NT server.

\subsection{SPECIFIC REQUIREMENTS}

Specific requirements of DocBasis are depicted in the following sections.

\subsection{FUNCTIONAL REQUIREMENTS}

Database must be access controlled and available to multiple users concurrently over the HLAN.

\subsection{EXTERNAL INTERFACE REQUIREMENTS}

All external interfaces are defined in the following sections.

\subsubsection{User Interfaces}

Programs must run in a networked PC environment. The data must reside on the HLAN for access by multiple users. The user interfaces must use Windows standard functionality. All programs must be built to run in Windows $3 x$ and Windows 95 environments.

\subsubsection{Hardware Interfaces}

Program availability on the HLAN in a PC networked environment requires that all software components are compatible to existing hardware including client machines, servers and server operating systems, network cards, and printers. The user community client machines have a minimum configuration 
of 486 DX-66, VGA monitors (with $800 \times 600$ resolution capabilities), Windows $3 \times$ with $8 \mathrm{mb}$. installed RAM or Windows 95 with $16 \mathrm{mb}$ installed RAM. Network printers are HPLJIII as minimum.

\subsubsection{Software Interfaces}

DocBasis allows other program (ARMI) to interface with other the procedure data contained within it for the download procedure status information.

\subsubsection{Communications Interfaces}

The database will be installed on an HLAN server running Windows NT. Program setup for client machines will be handled by the system. Client Machines will have ESOE installed.

\subsection{PERFORMANCE REQUIREMENTS}

It is anticipated that only a few users will have access to DocBasis. At this time, the only outside access is to the ARMI system administrator who has read only access

\subsection{DESIGN CONSTRAINTS}

Design constraints are defined in the following sections.

\subsubsection{Standards Compliance}

The software and accompanying databases and reports must be built in compliance with WHC. CM-3-10, Software Practices.

\subsubsection{Resource Limitations}

Compiled programs and supporting library files, databases, reports, and all other software components must be free of catastrophic or fatal errors. They must not violate the integrity of any client machine, server machine, or firewall on the HLAN.

\subsection{ATTRIBUTES}

The DocBasis software interface will protect the integrity of all data stored in the databases. The interface will make available all data in pick-list form wherever possible to ensure the integrity of data. The System Administrator user access level will be responsible for data backup.

The application must function in Windows for Workgroups ${ }^{1}$ and be expandable to Windows $95^{2}$. The application source code is to be stored separately by the System Administrator so that it is available whenever changes to the source code are necessary.

\subsection{OTHER REQUIREMENTS}

Other software requirements are listed in the following sections.

\subsubsection{Data.}

Prodecure data was imported by the system administrator to the databases from paradox

\footnotetext{
${ }^{1}$ Mcrosoft Corporation

2 Microsoft Corporation
} 
databases and ASCII or word processing text files. The System Administrator user access level will be responsible for data backup:

\subsubsection{Operations}

Software operation will follow Windows standards.

\subsubsection{Site Adaptation}

None.

\subsubsection{Options} at this time.

No other procedure-supported interface accessing the DocBasis table are known to be available

\subsubsection{Scheduling} maintenance.

The designated users who are provided access by the system administrator perform data

\subsubsection{Reliability and Recovery}

The software must be error free as defined in IEEE Std. $610.12-1990$, under the definition of error. The speed of operation must be within acceptable limits. Acceptable benchmark speed requirements are such that "the average software user will not be tempted to execute additional commands while the software is executing a current command."

\subsubsection{Audit.}

None.

\subsubsection{Priorities}

None

\subsubsection{Transferability}

There are no special implementation requirements. The software may be installed on any HLAN client machine meeting the installation specifications for hardware and operating system. The software may be distributed to other DOE sites by transferring the distribution set and current database.

\subsubsection{Conversion}

The programs must allow data import from text files (for requirement input) and output of specified report information to rich text format (RTF).

\subsubsection{Testing and Acceptance}

Upon final installation the user interface is final release according to national software standards. Formal verification and validation documentation is not required by PHMC procedures and is not available. 


\subsubsection{Documentation}

User manuals and System Administrator training guides are not required or provided.

\subsubsection{Training}

None required.

\subsubsection{Security and Privacy}

The software will provide limited program access to users based on installation of the interface program on their machine and access to the Procedures Group file server.

\subsection{DECOMPOSITION DESCRIPTION}

Not Applicable

\subsection{DEPENDENCY DESCRIPTION}

The are no dependencies.

\subsection{INTERFACE}

The DocBasis databases are Access Version 2.0. The user interface is built in Visual Basic $4.0^{3}$, the program is compiled in 16 bit to run on either Windows $3 . x$ or Windows 95 . The interface and database can be accessed on HLAN.

A breach of security could take place if a user has Access 2.0 and is allowed to open the DocBasis database. However, users access to the file server on which DocBasis is stored is restricted.

\subsection{MODULE}

The DocBasis user interface accesses the DocBasis.MDB.

\subsection{PROCESS INTERFACE}

Procedure data stored in DocBasis is accessed by the Authorization Basis Requirements Information (ARMI) program.

\subsection{DETAILED DESIGN} sections.

Detailed design information of the interface and DocBasis table is contained in the following

\subsection{INTERFACE DETAIL DESIGN}

A detailed design of the user interface is displayed graphically in Figure 7-1.

\footnotetext{
${ }^{3}$ Microsoft Corporation
} 
FIGURE 7-1 User Interface Detail

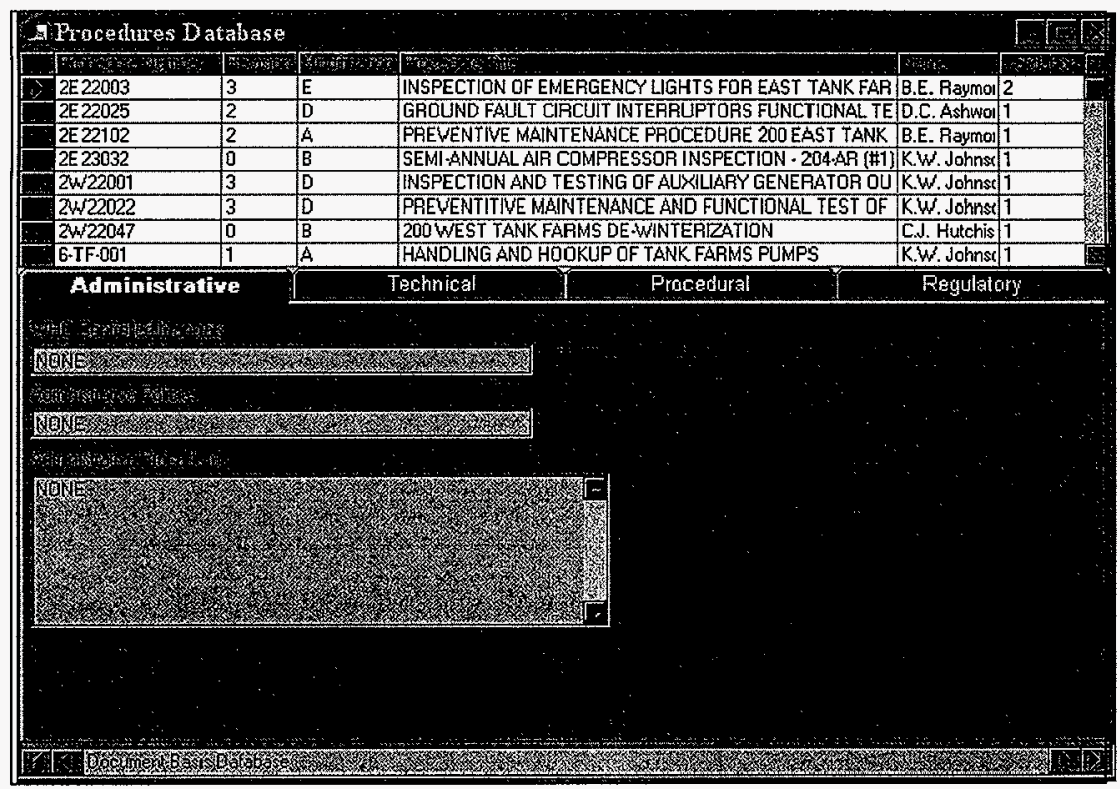

\subsection{DATA DETAIL DESIGN}

The DocBasis database consists of one data table called DocBasis. The attributes of the table are listed in the table below. The first three columns define the table structure attributes. The fourth column identifies those attributes that apply to each of the document basis categories.

TABLE 7-1 Data Detail Design

\begin{tabular}{|l|l|r|l|l|}
\hline \multicolumn{1}{|c|}{ Attribute } & Type & Size & \multicolumn{1}{c|}{ Description } & \multicolumn{1}{c|}{ Basis } \\
\hline Procedure Number & Text & 16 & Procedure number & Other \\
\hline Revision & Text & 2 & Revision letter & Other \\
\hline Modification & Text & 2 & Modification number & Other \\
\hline Procedure Title & Memo & & Procedure title & Other \\
\hline Name & Text & 20 & Author of the procedure & Other \\
\hline Assessment Validation & Text & 4 & Status of procedure validation & Other \\
\hline
\end{tabular}




\begin{tabular}{|c|c|c|c|c|}
\hline Attribute & Type & Size & Description & Basis \\
\hline Document Basis & Memo & & Reason for the procedure & Procedural \\
\hline $\begin{array}{l}\text { WHC Controlled } \\
\text { Manuals }\end{array}$ & Text & 50 & $\begin{array}{l}\text { WHC controlled manual } \\
\text { numbers }\end{array}$ & Administrative \\
\hline Administrative Policies & Text & 80 & Administrative policy numbers & Administrative \\
\hline $\begin{array}{l}\text { Administrative } \\
\text { Procedures }\end{array}$ & Memo & & $\begin{array}{l}\text { Administrative procedure } \\
\text { numbers }\end{array}$ & Administrative \\
\hline Technical Manuals & Text & 50 & Technical manual numbers & Technical \\
\hline Technical Procedures & Text & 50 & Technical procedure numbers & Technical \\
\hline Vendor Information & Text & 50 & Vender file numbers & Technical \\
\hline Training Instructor & Text & 25 & Training instructor name & Procedural \\
\hline Certification Number & Text & 25 & Training certification & Other \\
\hline Drawings & Memo & & Drawing numbers & Technical \\
\hline Software & Text & 30 & Server address of procedure & Procedural \\
\hline Occurrence Reports & Memo & & Occurrence report numbers & Technical \\
\hline Safety Analyses & Text & 100 & $\begin{array}{l}\text { Safety analysis document } \\
\text { number }\end{array}$ & Technical \\
\hline DOE Orders & Text & 25 & DOE Order document numbers & Regulatory \\
\hline OSHA Standards & Text & 25 & $\begin{array}{l}\text { OSHA Standard document } \\
\text { numbers }\end{array}$ & Regulatory \\
\hline Code of Federal Regs & Text & 50 & $\begin{array}{l}\text { Federal regulation code } \\
\text { numbers }\end{array}$ & Regulatory \\
\hline Permits/Regulations & Text & 50 & $\begin{array}{l}\text { Permits/regulation document } \\
\text { numbers }\end{array}$ & Regulatory \\
\hline Components & Text & 25 & $\begin{array}{l}\text { Components relating to the } \\
\text { procedure }\end{array}$ & Technical \\
\hline $\begin{array}{l}\text { Technical } \\
\text { Specifications }\end{array}$ & Memo & & $\begin{array}{l}\text { Technical spec document } \\
\text { numbers }\end{array}$ & Technical \\
\hline Criticality Specs & Text & 50 & $\begin{array}{l}\text { Criticality spec document } \\
\text { numbers }\end{array}$ & Technical \\
\hline Procedure Changes & Memo & & $\begin{array}{l}\text { Notes about procedure } \\
\text { changes }\end{array}$ & Procedural \\
\hline Other & Memo & & Other document numbers & Procedural \\
\hline
\end{tabular}




\subsection{REFERENCES}

Software Practices, WHC-CM-3-10, SP-3.1.

Software Practices, WHC-CM-3-10 Appendix A. 